- I Forum of Regional Actors for Road Safety in Latin America and the Caribbean (Costa Rica, 2007)

- International Congress of Transportation and Urban Development of the Americas (Costa Rica, 2006).

\section{ROAD SAFETY FOR COMMERCIAL FLEET}

D Serrano Quiros* Correspondence: DHL Global Forwarding, $800 \mathrm{mts}$ NO de interseccion Real Cariari, La Aurora, America Central, Heredia, 1399-3000, Costa Rica

\subsection{6/ip.2010.029215.409}

This programme is based on accident prevention for Vehicle Commercial Fleet in order to reduce lost days due to disability from road accidents. Driving a commercial vehicle represents major risk due to its characteristics: lack of preventive maintenance, prolonged times of driving and bad driving practices.

This programme consists of:

1. safe driver profile

2. medical control

3. preventive maintenance

4. social responsibility and projection to the community

5. disclosure and training workshops on road safety

6. risks identification and assessment.

It began as an integral experimental project within DHL Global Forwarding, a company with a vast vehicle fleet in 2004. During that year, the lost days due to road accidents were 247; while in 2005 it improved by having 115 lost days. In 2006 this number dropped down to 67 days and as of now, the count is as of 0 days lost due to road accidents.

Strategies to follow To present this programme for its reproducibility in different sectors. The strategy is that of disclosure in forums, schools, civil community and interested governments in order to achieve better road behaviour.

This programme had been declared as of Scientific Interest in different International Forums:

- 9th World Conference on Injury Prevention and Safety Promotion (Mexico, 2008)

- I Iberian-American Congress for Road Safety (Costa Rica, 2008) 